\title{
Mid-term Results of Total Knee Arthroplasty Using PFC Sigma RP-F
}

\author{
Jun-Young Kim, MD, Sang-Ho Cheon, MD and Hee-Soo Kyung, MD, PhD \\ Department of Orthopaedic Surgery, Kyungpook National University School of Medicine, Daegu, Korea
}

Purpose: We compared the mid-term results after total knee arthroplasty (TKA) using PFC Sigma RP-F mobile model with PFC Sigma PS fixed model.

Materials and Methods: We analyzed 45 knees that underwent TKA with PFC Sigma RP-Fn (study group) and 45 knees with PFC Sigma PS (control group). The mean follow-up period was 65 months (range, 60-69 months). The evaluation system of the American knee society was used for clinical and radiological assessment. Also, the maximal knee flexion angle was assessed.

Results: The mean maximum flexion angle in the study group $\left(135^{\circ}\right)$ was greater than that in the control group $\left(125^{\circ}\right)$ at the early post-operation \& final follow-up period ( $\mathrm{p}=0.033)$. The range of motion $(\mathrm{ROM})$ in the study group was recovered earlier at the postoperative 6 months, and ROM gain was improved to a greater extent at the final follow-up period $(\mathrm{p}=0.039)$. The knee score and function score and radiographic evaluation were no difference between the two groups ( $\mathrm{p}>0.05$ ) at the final follow-up. The two cases of radiolucency in posterior condyle and medial tibial plateau and one case of patellar elongation were seen in the study group.

Conclusions: The PFC Sigma RP-F mobile system appears to facilitate greater maximum flexion angle and ROM gain with two cases of radiolucent line.

Key words: Total knee arthroplasty, Sigma RP-F mobile model, Mid-term result, High-flexion implant.

\section{Introduction}

The purpose of total knee arthroplasty (TKA) is to maintain the function and stability of the knee joint and relieve pain. Postoperative limitation of knee flexion can cause disruption of daily living activities in Asian patients due to their culture of sitting on the floor ${ }^{1)}$. The increasing participation in leisure and sports activities, including golf and bowling, has led patients to expect to obtain as normal range of motion (ROM) of the knee

Received July 9, 2012; Revised August 16, 2012;

Accepted September 20, 2012.

Correspondence to: Hee-Soo Kyung, MD.

Department of Orthopaedic Surgery, Kyungpook National University School of Medicine, 130 Dongduk-ro, Jung-gu, Daegu 700-721, Korea. Tel: +82-53-420-5636, Fax: +82-53-422-6605

Email: hskyung@knu.ac.kr

This is an Open Access article distributed under the terms of the Creative Commons Attribution Non-Commercial License (http://creativecommons.org/licenses/by-nc/3.0/) which permits unrestricted non-commercial use, distribution, and reproduction in any medium, provided the original work is properly cited. as possible after surgery. The primary factors that influence postoperative ROM include the diagnosis, preoperative ROM and deformity, age, gender, surgical technique, postoperative pain control and rehabilitation, and lifestyle ${ }^{2,3)}$. Implant design is another important factor for a satisfactory ROM after TKA, and thus, high flexion knee prostheses have been introduced. Compared to the PFC Sigma RP fixed model that allows axial rotation between the polyethylene insert and tibial component, the PFC Sigma RP-F mobile model that has a thicker posterior femoral condyle to minimize polyethylene contact stresses during high flexion incorporates advantages of the mobile-bearing and high flexion models ${ }^{4-6)}$.

However, some high-flexion models have been associated with the high incidence of early aseptic loosening that results from the increased shear force between the femur and the femoral component during high flexion ${ }^{7)}$. Cho et al. ${ }^{8)}$ reported that radiolucent lines were observed in $13.8 \%$ of the cases between 3-6 years after high-flexion TKA, 3.2\% of which required reoperation at a mean of 49 months postoperatively. Han et al. ${ }^{7)}$ observed aseptic loosening in 38\% of the patients at a mean of 32 months after high-flexion TKA, and $21 \%$ of which underwent reoperation at a mean of 32 months postoperatively. 
In this study, we hypothesized that TKA using PFC Sigma RP-F mobile model would result in greater range of maximum flexion without the risk of early aseptic loosening compared to TKA using PFC Sigma PS fixed model and analyzed the clinical and radiological outcomes of TKAs using the two different models.

\section{Materials and Methods}

A total of 121 primary TKAs were performed for osteoarthritis between February 2005 and October 2005 at our institution. PFC Sigma RP-F mobile (DePuy Orthopaedics Inc., Warsaw, IN, USA) or PFC Sigma PS fixed (DePuy Orthopaedics Inc.) model was used for the surgery in 100 of the cases. Of these, 90 cases (65 patients) that were available for minimum 5 years of follow-up were retrospectively reviewed for this study. The exclusion criteria were $\geq 30^{\circ}$ flexion contracture, $\geq 20^{\circ}$ varus deformity, and $\geq 30$ body mass index (BMI). In the PFC Sigma RP-F mobile model TKA group (study group), there were 45 cases (35 patients; 3 males and 32 females) with a mean age of 67.1 years (range, 5279 years). In the PFC Sigma PS fixed model TKA group (control group), there were 45 cases ( 30 patients). There was no significant intergroup difference in terms of the age, gender, BMI, and patella resurfacing. The mean follow-up period was 65 months (range, 60-69 months) (Table 1).

All the operations were performed by the same surgeon using a standard medial parapatellar approach. Extension and flexion gap balancing was performed, using the gap technique and measured resection technique. Cement was used for fixation of the tibial and femoral components in all cases. Cementing was initiated on the tibia followed by femur and patella. The cement was applied on the surface of the implants, resected bone surface, and posterior cut of the femur, while exerting pressure with fingers prior to fixation. When the cement was completely hardened with pressure applied to the axis of the joint longitudinally, the tourniquet was released. After hemostasis was obtained, the trial polyethylene component and extra cement were removed and a

Table 1. Comparison of Patients between the Study Group and Control Group

\begin{tabular}{lccc}
\hline & $\begin{array}{c}\text { Study group } \\
(\mathrm{n}=45)\end{array}$ & $\begin{array}{c}\text { Control group } \\
(\mathrm{n}=45)\end{array}$ & $\mathrm{p}$-value \\
\hline Model & Sigma RP-F & Sigma PS & - \\
F/M & $32 / 3$ & $26 / 4$ & 0.051 \\
Age & $67.1(52-79)$ & $67(61-75)$ & 0.414 \\
Body mass index & $26.5(21.3-30)$ & $24.8(20-29.5)$ & 0.250 \\
Patellar retention (case) & 40 & 39 & 0.470 \\
\hline
\end{tabular}

real polyethylene component was inserted.

The postoperative rehabilitation program was identical in both groups. Quadriceps femoris strengthening exercises were initiated from the 1st postoperative day. Continuous passive motion (CPM) using a machine was allowed from the 3rd postoperative day to promote rapid recovery. If straight-leg-raising was possible and quadriceps muscle strength was recovered, crutch walking with a brace was allowed.

Follow-up examinations were performed at 6 weeks, 3 months, and 6 months after surgery and once a year thereafter. The postoperative ROM was assessed at 6 weeks, 3 months, 6 months, and 2 years after surgery, and at the last follow-up. For the assessment of ROM, active flexion angle on the sagittal plane digital image taken without weight bearing was measured with anterior surface of leg and thigh using the Image J program (Wayne Rasband, NIH, Bethesda, MD, USA) (Fig. 1) ${ }^{9)}$. The preand postoperative ROM measurements were performed by two orthopedic surgeons ( $\mathrm{p}=0.77$ ).

For clinical assessment, the knee score and function score according to the Knee Society clinical rating system were measured preoperatively and at the last follow-up ${ }^{10)}$. For radiographic assessment, anteroposterior (AP) radiographs of both legs and lateral radiographs taken with the knee in $30^{\circ}$ flexion were obtained preoperatively and at the last follow-up. These radiographs were assessed according to the Knee Society roentgenographic evaluation and scoring system ${ }^{11}$.

Statistical analysis was done using the SPSS ver. 17 (SPSS Inc., Chicago, IL, USA). T-test was used for comparison of quantitative parameters, including the flexion angle, knee score,

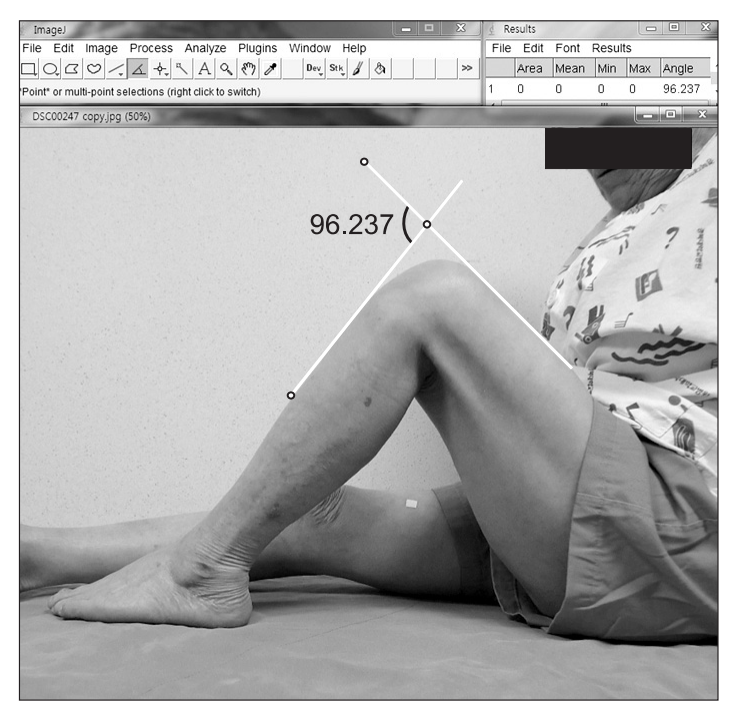

Fig. 1. The range of motion of the knee was measured by digital imaging technique introduced by Bennett et al. ${ }^{9)}$. 
and radiographic measurements. The Chi-square test was used for nominal parameters, including the male to female ratio and patella resurfacing. A $p<0.05$ was considered statistically significant. The minimum sample size was 39 patients for each group when a power analysis was conducted based on the following assumptions: maximum flexion angle difference $=10^{\circ}$, standard deviation $=15^{\circ}$, significance level $=0.05, \beta$-error $=0.2$, and dropout rate $=10 \%$.

\section{Results}

There were no statistically significant intergroup differences in the flexion contracture preoperatively $(\mathrm{p}=0.252)$ and during the follow-up. The maximum flexion angle was smaller immediately postoperatively compared to the preoperative value, but increased progressively until the 2 nd postoperative year and was maintained until the last follow-up. The mean maximum flexion angle was not significantly different between the groups preoperatively, but was notably greater in the study group $\left(135^{\circ} \pm 6^{\circ}\right)$ than the control group $\left(125^{\circ} \pm 7^{\circ}\right)$ at the last follow-up $(\mathrm{p}=0.033)$ (Table 2).

The mean change in the maximum flexion angle ( $\Delta$ flexion) between the preoperative and follow-up examinations was significantly different between the groups. The $\Delta$ flexion was greater in the study group until the 6 th postoperative month. The $\Delta$ flexion at the last follow-up was $5^{\circ}$ in the study group and $-3^{\circ}$ in

Table 2. Range of Motion between the Study Group and Control Group

\begin{tabular}{|c|c|c|c|c|c|c|c|c|}
\hline & \multicolumn{3}{|c|}{ Study group } & \multicolumn{3}{|c|}{ Control group } & \multicolumn{2}{|c|}{ p-value } \\
\hline & $\begin{array}{c}\text { Flexion } \\
\text { contracture }\end{array}$ & $\begin{array}{c}\text { Maximal } \\
\text { flexion }\end{array}$ & $\Delta$ Flexion & $\begin{array}{c}\text { Flexion } \\
\text { contracture }\end{array}$ & $\begin{array}{c}\text { Maximal } \\
\text { flexion }\end{array}$ & $\Delta$ Flexion & $\begin{array}{c}\text { Maximal } \\
\text { flexion }\end{array}$ & $\Delta$ Flexion \\
\hline Preop ROM $\left(^{\circ}\right)$ & $9.4 \pm 6.4$ & $130.0 \pm 5.0$ & - & $15.0 \pm 4.4$ & $128.0 \pm 6.0$ & - & 0.434 & - \\
\hline POP 6 wk $\left({ }^{\circ}\right)$ & $4.4 \pm 5.2$ & $114.3 \pm 5.0$ & -15.7 & $3.5 \pm 6.0$ & $104.5 \pm 5.0$ & -20.5 & 0.035 & 0.040 \\
\hline POP $3 \mathrm{mo}\left({ }^{\circ}\right)$ & $3.5 \pm 6.2$ & $119.6 \pm 5.2$ & -10.4 & $1.0 \pm 2.7$ & $109.0 \pm 6.2$ & -16.0 & 0.032 & 0.043 \\
\hline POP 6 mo $\left({ }^{\circ}\right)$ & $4.4 \pm 6.4$ & $134.4 \pm 6.2$ & +4.4 & $3.5 \pm 6.1$ & $120.0 \pm 8.1$ & -5.0 & 0.021 & 0.041 \\
\hline POP 2 yr $\left({ }^{\circ}\right)$ & $1.0 \pm 6.0$ & $135.1 \pm 6.1$ & +5.1 & $2.0 \pm 4.8$ & $124.5 \pm 7.8$ & -3.5 & 0.031 & 0.040 \\
\hline Final F/U $\left(^{\circ}\right)$ & $0 \pm 5.0$ & $135.0 \pm 6.0$ & +5.0 & $0 \pm 4.5$ & $125.0 \pm 7.0$ & -3.0 & 0.033 & 0.039 \\
\hline
\end{tabular}

Preop: preoperative, POP: postoperation, ROM: range of motion, F/U: follow-up, $\Delta$ flexion: maximal flexion angle gain.
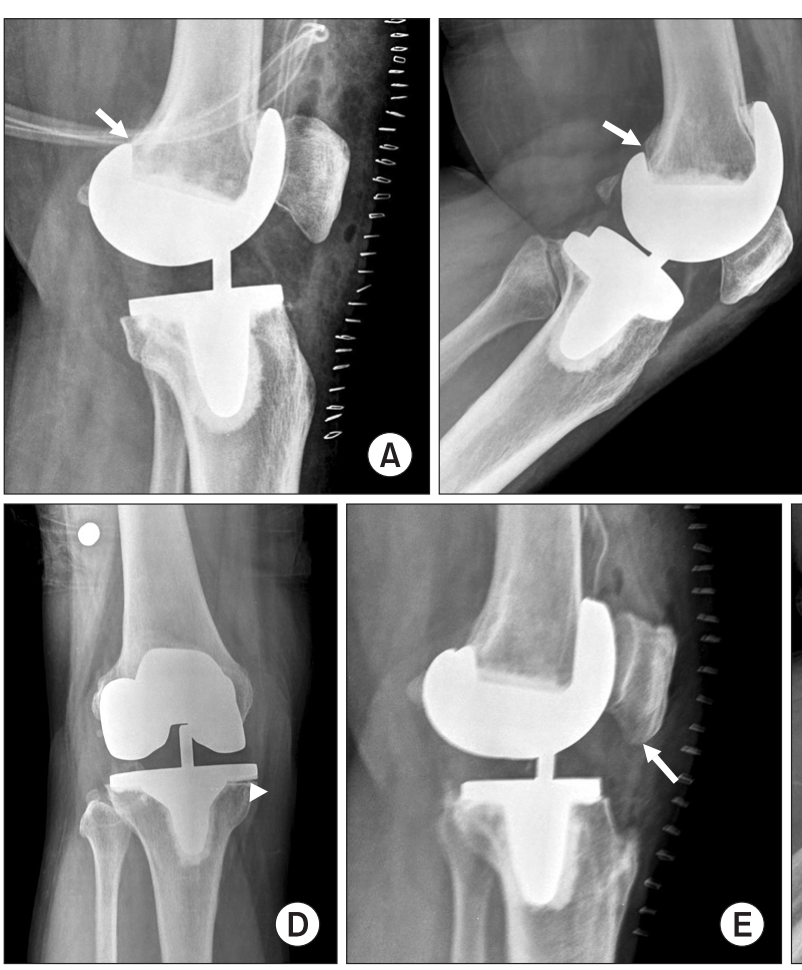

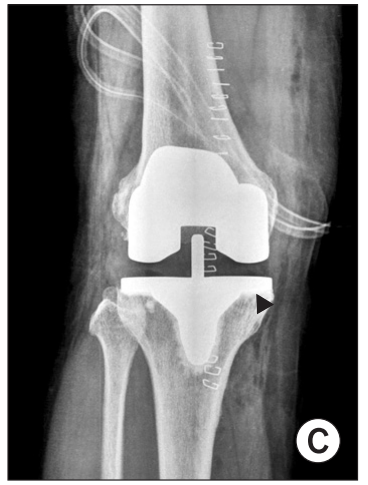

c

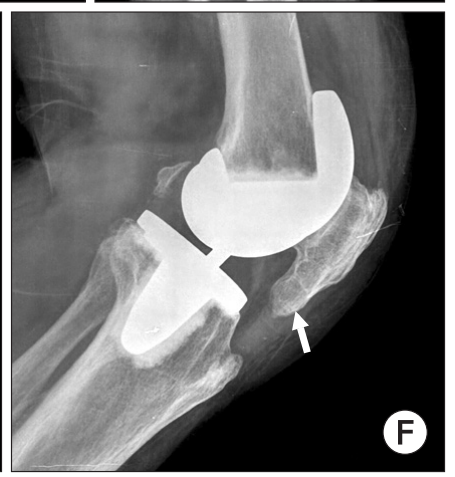

Fig. 2. The two cases of radiolucent line and one case of patellar elongation were seen in the study group. (A) Immediate postoperative view shows no visible radiolucent line in the posterior femoral condyle (arrow). (B) Radiolucent line in the posterior femoral condyle (arrow) is seen at follow-up 62 months. (C) Immediate postoperative view shows no visible radiolucent line in the medial tibial plateau is seen (arrowhead). (D) Radiolucent line in the medial tibial plateau is seen (arrowhead) at the follow-up 65 months. (E) Immediate postoperative view shows no visible patellar abnormality (arrow). (F) Patellar elongation is seen (arrow) at follow-up 65 months. 
the control group $(\mathrm{p}=0.039)$ (Table 2).

In the study group, the mean knee score and function score were improved from $56.1 \pm 10.0$ preoperatively to $93.4 \pm 5.0$ at the last follow-up and from $55.2 \pm 9.1$ preoperatively to $90.0 \pm 10.0$ at the last follow-up, respectively. In the control group, the mean knee score and function score were improved from 55.2 \pm 7.1 preoperatively to $92.0 \pm 8.1$ at last follow-up and from $58.1 \pm 5.1$ preoperatively to $89.5 \pm 8.2$ at last follow-up, respectively. No statistically significant differences were observed between the groups in the clinical assessment ( $\mathrm{p}>0.05$ ).

On the radiographic assessment using the Knee Society radiographic scoring system, the $\alpha$ angle was $96.2^{\circ} \pm 1.3^{\circ}, \beta$ angle was $89.9^{\circ} \pm 1.0^{\circ}, \gamma$ angle was $3.2^{\circ} \pm 1.0^{\circ}$, and $\delta$ angle was $87.0^{\circ} \pm 2.5^{\circ}$ in the study group, whereas the $\alpha$ angle was $95.9^{\circ} \pm 1.5^{\circ}, \beta$ angle was $88.9^{\circ} \pm 1.3^{\circ}, \gamma$ angle was $3.2^{\circ} \pm 1.2^{\circ}$, and $\delta$ angle was $87.0^{\circ} \pm 2.4^{\circ}$ in the control group, showing no statistically significant intergroup differences $(p>0.05)$. However, radiolucent lines were observed in the posterior femoral condyle in 1 case and medial tibial condyle in 1 case in the study group, although reoperation was not necessary due to the absence of symptoms. Patellar elongation was found in 1 case in the study group (Fig. 2). Prosthesis-related complications were not observed and reoperation was not required in any of the cases.

\section{Discussion}

In this study, high-flexion TKA resulted in greater maximum flexion angle than conventional TKA without significant complications, such as implant loosening. The PFC Sigma RP-F model used in this study is a mobile-bearing design that allows axial rotation between the tibial component and the polyethylene insert and high flexion by promoting posterior translation of the femur. Although the thicker and higher posterior femoral component design requires greater resection of the posterior femoral condyle, it is designed to minimize stresses on the prosthesis to enable $155^{\circ}$ of flexion ${ }^{4-6)}$. However, $155^{\circ}$ of flexion is rarely possible because high flexion is affected by a variety of factors, including the diagnosis, preoperative ROM and deformity, age, gender, surgical technique, postoperative pain management and rehabilitation, and life style. Most of the conventional knee implants, including the PFC Sigma PS model, are designed to allow $120^{\circ}$ of flexion ${ }^{12,13}$. In this study, the mean maximal flexion angle was $125^{\circ}$ at 5 years after TKA using the PFC Sigma PS model.

Bin and $\mathrm{Nam}^{14)}$ reported that the high flexion knee prosthesis, Nexgen LPS, was more effective in restoring maximal flexion angle than the conventional implants. The results were notable especially in patients with $<90^{\circ}$ of preoperative maximal flexion angle. In the current study, patients with degenerative osteoarthritis obtained excellent results (the mean maximal flexion angle, $135^{\circ}$ ) at 5 years after TKA using the PFC Sigma RP-F model. There are many short-term follow-up studies showing that the flexion angle and the maximal flexion angle are $27^{\circ}$ greater after TKA using the Sigma RP-F model than TKA using the conventional implants ${ }^{4,15-18}$. Gupta et al. ${ }^{4)}$ reported that the mean increase in flexion angle was $10^{\circ}$ greater in the PFC Sigma RP-F group than the PFC Sigma RP group. Suh et al. ${ }^{18)}$ reviewed the results of 41 cases of TKA using Sigma RP-F or Sigma PS for a mean period of 26.7 months. The mean maximum flexion angle was greater in the Sigma RP-F group $\left(130.4^{\circ}\right)$ than the Sigma PS group $\left(123.3^{\circ}\right)$, whereas no significant intergroup difference was found in the clinical outcomes, which is in agreement with our study results. Maniar and Singhi ${ }^{19)}$ followed up 52 cases of TKA using the Sigma RP-F model for a mean period of 50.2 months (range, 26-72 months). In the study, the mean postoperative knee flexion angle was $130^{\circ}$ and the survival rate was $100 \%$, and there was no case of component loosening or osteolysis. In contrast, Kim et al. ${ }^{20)}$ reported there was no statistically significant difference in the flexion angle between the NexGen LPS-flex group and the conventional implant group. Many clinical studies have shown that mobile-bearing and fixedbearing implants did not result in differences in terms of flexion angle and knee score ${ }^{21-25)}$.

Massin et al. ${ }^{26)}$ reported that improvements in flexion was not correlated with the postoperative function score. In the current study, the increase in maximal flexion angle was significantly greater by $10^{\circ}$ in the study group, whereas there were no significant differences between the two groups in the knee score and function score.

Cho et al. ${ }^{8)}$ evaluated 3 to 6 years of follow-up results of NexGen LPS-flex TKA. Progressive radiolucent lines were observed in 30 (13.8\%) of 218 cases, 7 (3.2\%) of which required reoperation at 49 months postoperatively. Han et al. ${ }^{7}$ reported that aseptic loosening occurred in 27 (38\%) of the 72 cases at a mean of 32 months after NexGen LPS-flex TKA and reoperation was necessary in 15 cases $(21 \%)$ at a mean of 23 months postoperatively. In the current study, although radiolucent lines were observed in 2 cases at $\geq 5$ years after PFC Sigma RP-F TKA, the overall results were good without any presence of symptoms or complications, including component loosening and polyethylene wear. We attributed this to the differences in the cementing technique and implant design. 
The limitations of this study include that different influences of the mobile-bearing and fixed-bearing implants were not reflected in the outcomes, the number of cases was small, and the followup period was short. We believe that the incidence of component loosening and osteolysis should be assessed in future studies that involve a long-term follow-up and a larger study population.

\section{Conclusions}

The mid-term follow-up results of TKA using the PFC Sigma RP-F mobile model showed that the high-flexion knee prosthesis facilitates greater maximum flexion compared to the conventional implant. Radiolucency was observed in 2 cases. However, the high flexion model did not make a significant difference regarding the knee score and function score compared to the conventional model.

\section{References}

1. Yamazaki J, Ishigami S, Nagashima M, Yoshino S. Hy-Flex II total knee system and range of motion. Arch Orthop Trauma Surg. 2002;122:156-60.

2. Dennis DA, Komistek RD, Scuderi GR, Zingde S. Factors affecting flexion after total knee arthroplasty. Clin Orthop Relat Res. 2007;464:53-60.

3. Harvey IA, Barry K, Kirby SP, Johnson R, Elloy MA. Factors affecting the range of movement of total knee arthroplasty. J Bone Joint Surg Br. 1993;75:950-5.

4. Gupta SK, Ranawat AS, Shah V, Zikria BA, Zikria JF, Ranawat CS. The P.F.C. sigma RP-F TKA designed for improved performance: a matched-pair study. Orthopedics. 2006;29:S49-52.

5. Jones RE. High-flexion rotating-platform knees: rationale, design, and patient selection. Orthopedics. 2006;29:S76-9.

6. Ranawat AS, Gupta SK, Ranawat CS. The P.F.C. sigma RP-F total knee arthroplasty: designed for improved performance. Orthopedics. 2006;29:S28-9.

7. Han HS, Kang SB, Yoon KS. High incidence of loosening of the femoral component in legacy posterior stabilised-flex total knee replacement. J Bone Joint Surg Br. 2007;89:145761.

8. Cho SD, Youm YS, Park KB. Three- to six-year followup results after high-flexion total knee arthroplasty: can we allow passive deep knee bending? Knee Surg Sports Traumatol Arthrosc. 2011;19:899-903.

9. Bennett D, Hanratty B, Thompson N, Beverland D.
Measurement of knee joint motion using digital imaging. Int Orthop. 2009;33:1627-31.

10. Insall JN, Dorr LD, Scott RD, Scott WN. Rationale of the Knee Society clinical rating system. Clin Orthop Relat Res. 1989;(248):13-4.

11. Ewald FC. The Knee Society total knee arthroplasty roentgenographic evaluation and scoring system. Clin Orthop Relat Res. 1989;(248):9-12.

12. Li G, Most E, Otterberg E, Sabbag K, Zayontz S, Johnson T, Rubash H. Biomechanics of posterior-substituting total knee arthroplasty: an in vitro study. Clin Orthop Relat Res. 2002;(404):214-25.

13. Hendel D, Garti A, Weisbort M. Fracture of the central polyethylene tibial spine in posterior stabilized total knee arthroplasty. J Arthroplasty. 2003;18:672-4.

14. Bin SI, Nam TS. Early results of high-flex total knee arthroplasty: comparison study at 1 year after surgery. Knee Surg Sports Traumatol Arthrosc. 2007;15:350-5.

15. Maniar RN, Tushar S, Singh A, Gupta H, Nanivadekar A, Maniar PR. Postoperative flexion analysis of 3 rotatingplatform knee designs. Orthopedics. 2012;35:e1159-65.

16. Massin P, Dupuy FR, Khlifi H, Fornasieri C, De Polignac T, Schifrine P, Farenq C, Mertl P. Does hyperflex total knee design improve postoperative active flexion? Orthop Traumatol Surg Res. 2010;96:376-80.

17. Nutton RW, Wade FA, Coutts FJ, van der Linden ML. Does a mobile-bearing, high-flexion design increase knee flexion after total knee replacement? J Bone Joint Surg Br. 2012;94:1051-7.

18. Suh JT, Shin WC, Ahn TY. The total knee arthroplasty with PFC Sigma RP-F(R): two year short-term results. J Korean Orthop Assoc. 2008;43:57-64.

19. Maniar RN, Singhi T. High-flex rotating platform knee implants: two- to 6-year results of a prospective study. J Arthroplasty. 2012;27:598-603.

20. Kim YH, Sohn KS, Kim JS. Range of motion of standard and high-flexion posterior stabilized total knee prostheses. A prospective, randomized study. J Bone Joint Surg Am. 2005;87:1470-5.

21. Aglietti P, Baldini A, Buzzi R, Lup D, De Luca L. Comparison of mobile-bearing and fixed-bearing total knee arthroplasty: a prospective randomized study. J Arthroplasty. 2005;20:14553.

22. Ranawat AS, Rossi R, Loreti I, Rasquinha VJ, Rodriguez JA, Ranawat CS. Comparison of the PFC Sigma fixed-bearing and rotating-platform total knee arthroplasty in the same 
patient: short-term results. J Arthroplasty. 2004;19:35-9.

23. Woolson ST, Northrop GD. Mobile- vs. fixed-bearing total knee arthroplasty: a clinical and radiologic study. J Arthroplasty. 2004;19:135-40.

24. Kim TW, Park SH, Suh JT. Comparison of mobile-bearing and fixed-bearing designs in high flexion total knee arthroplasty: using a navigation system. Knee Surg Relat Res. 2012;24:25-33.
25. Suh JT, Kim TW, Ahn TY. Comparison of the mobilebearing and fixed-bearing designs for high flexion total knee arthroplasty. J Korean Knee Soc. 2010;22:165-74.

26. Massin P, Lautridou C, Cappelli M, Petit A, Odri G, Ducellier F, Sabatier C, Hulet C, Canciani JP, Letenneur J, Burdin P. Total knee arthroplasty with limitations of flexion. Orthop Traumatol Surg Res. 2009;95:S1-6. 